\title{
Residential built environments: the importance of social capital.
}

\author{
Ms. Kirti D. Bhonsle ${ }^{1}$, Dr. V. S.Adane ${ }^{2}$, \\ ${ }^{I}$ (Institute of Design Education and Architecture Studies,Nagpur,Maharashtra, India) \\ ${ }^{2}$ (Visvesveraya Nationa Institute of Technology, Nagpur, Maharashtra, India)
}

\begin{abstract}
Man is a part of nature but with the growth and development of civilization with higher levels of urbanization he is more close to manmade environment as compared to the natural environment which is thus influencing the way he thinks, behaves and acts. So also man being a social animal cannot be kept aside from socializing which is a major factor for his physical, mental and social satisfaction. Through this brief literature review I have been able to arrive at a hypothesis that, residential satisfaction is more a function of the social capital of a neighborhood and enhancing it by the use of incidental open spaces along with the interdependent communities may help achieve better environments.
\end{abstract}

Keywords - Residential built environment, residential satisfaction, social capital, interdependent communities.

\section{Introduction}

"Environment influences us even before we are born". The foetus in the mother's womb has an environment and is not a mindless mass of flesh but a highly responsive and evolving human being, capable of receiving, understanding and responding to external stimuli. It therefore follows that the foetus has a right to receive positive and enriching feedback or Garbha sanskar. Thoughts and feelings of the parents affect the baby. Even before the thought is expressed, it remains in an unexpressed form in the mind. At that time, its wavelength is the shortest and its energy is at the maximum level. Intentional, directed, selfless, unspoken thoughts lead to maximum sanskar on the foetus. This can very well establish the degree of concern we as architects should have to giving a positive environment to those who are a part of a space in some way or the other.

Environment is a crucial piece of the puzzle when you look at behavior because your brain reacts profoundly to its surrounding environment. It also means a bounded set of physical or virtual structures, functions or events where people interact. Behavior refers to the actions of a system or organism, usually in relation to its environment, which includes the other systems or organisms around as well as the physical environment. The interface of environment and people is a matter of study wherein there are various types of environments like -

- Natural environment

- Social environments

- Built environments

- Learning environments

- Informational environments

\section{The Built Environment}

Movements to protect or restore the environment have focused somewhat narrowly on natural systems, neglecting the idea that the environments with which people interact most directly are often products of human initiated process. Collectively these products of and processes of human creation are called the built environment. This term is comparatively new, but it describes in one holistic and integrated concept the creative results of human activities throughout history. The term emerged in the 1980's and came in widespread use in the 1990's.

Most of the society's knowledge of the past civilizations is derived from remnants of the built environment. Similarly, present cultures will be judged in the future by what they have created.

Will the results be profound and expressive of the very best of society?

Or

Will the results be condemned as careless of healthy human-environmental relationships?

The built environment is pervasive but the term, its reach and its implications are evasive, more comprehensive and far reaching. The built environment can be defined by its four interrelated characteristics First it is extensive: it is everywhere, it provides the context for all human endeavors [everything humanly created, modified, or constructed, humanly made, arranged or maintained.

Second it is the creation of the human mind, needs, purpose, wants and values. 
Third it is created to help us deal with and protect us from, the overall environment, to mediate or change this environment for our comfort and well being.

Fourth- all the components of the built environment is defined and shaped by context.

Each and all of the individual elements contribute either positively or negatively to the overall quality of the environments both built and natural and to human-environment relationships.

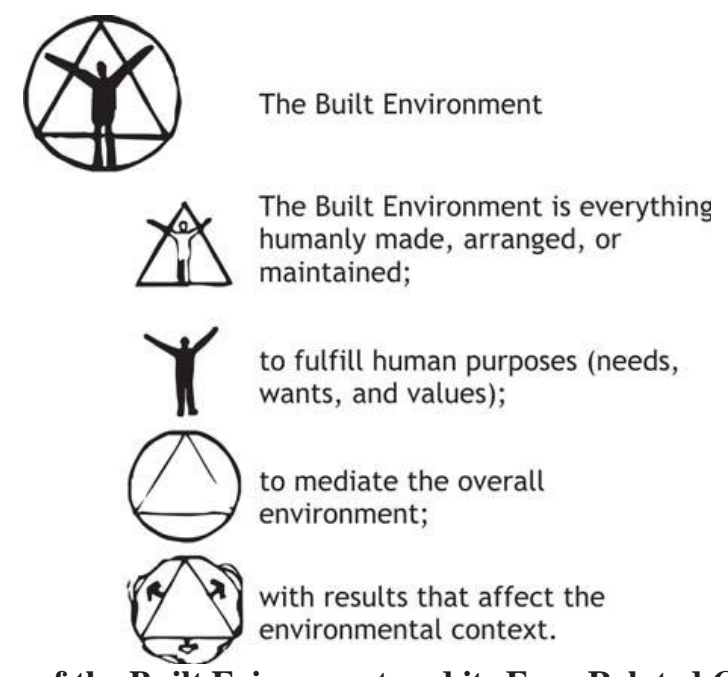

Fig. 1 Definition of the Built Evironment and its Four Related Characteristics.

${ }^{[1]}$ Source:The Built Environment, a collaboration inquiry into Design and Planning, second edition, 2007, edited by Wendy R. McClure and Tom J. Bartuska

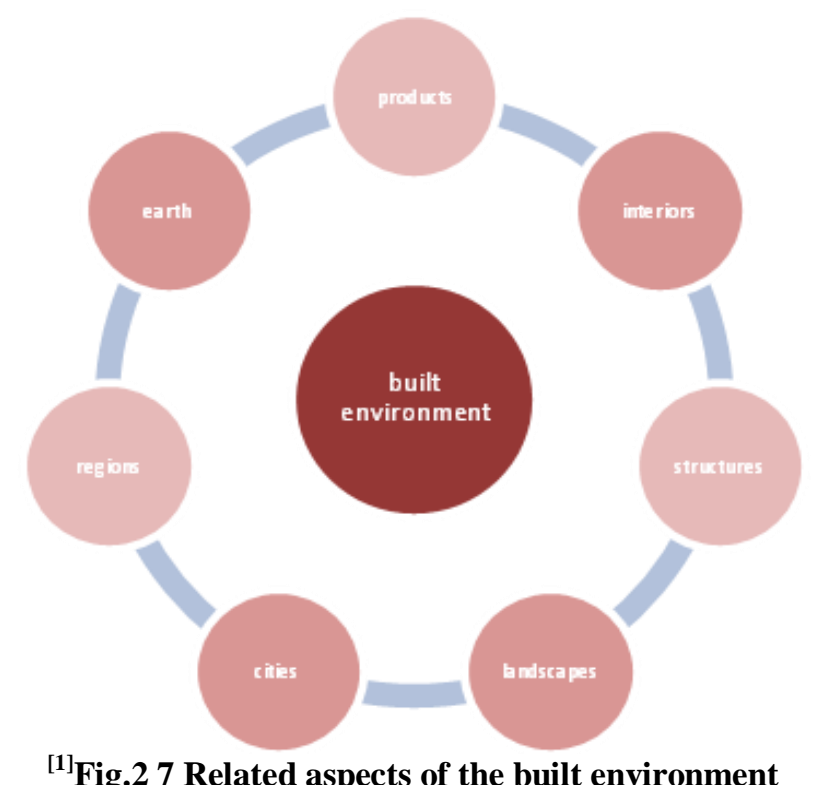

\subsection{SCOPE OF THE BUILT ENVIRONMENT}

There is a significant overall theme: the interrelationships of each of the component with each of the others. The content of each component consists of a combination of smaller components. In turn each component is a part of a larger context and contributes to the next larger component. The hierarchy of the content-component-context is adopted to understand that the human needs are manifested in the built environments.

\section{The Residential Environment}

Residential environment stands for physical and social space referred to in subjective feeling and in the behavior of its residents that includes any population group or physical environment referred to by residents. 
Each residential environment will be characterized by its own sense of place and there are many social and physical factors influencing it. The residential environments can be typified by objective criteria such as building period, architectural style, spatial structure, amount of given space and geographical location.

${ }^{[2]}$ Churchman and Rosenfeld [1978] state that the term residential environment refers to the dimensions and boundaries that are significant to the residents themselves and to the social relations and activities they want to conduct there.

${ }^{[3]}$ Hallman [1984] has found that, the residential environment allows us to distinguish between the physical boundaries of the neighborhoods as defined by the local authority for the purpose of urban organization and the boundaries of more limited areas as subjectively perceived by their residents.

${ }^{[4]}$ Rappoport [1980-81, 1997] claims that since the definition of space are partially based upon physical and social images, the variables of the definition are not only the area and its dimensions but also the degree of overlap between social and physical space. Billing and Churchman [2003] have found that physical boundaries affect the attitudes and behaviors of residents.

\begin{tabular}{|l|}
\hline Parameters of residential built environment \\
\hline Green space \\
\hline Density \\
\hline Road \\
\hline Convenience \\
\hline Clean environment \\
\hline Noise and safety \\
\hline Visual character \\
\hline Community facilities \\
\hline Utilities \\
\hline Human services \\
\hline Community development activities \\
\hline
\end{tabular}

The various user groups are important to us as their perceptions change with age, gender, occupation etc. Hence the various users of the environments can be categorized as -

\section{Table - 2 Categories of People}

The human-environment interaction has five major components. These components are briefly described below:
Apart from the standards of neighborhoods and their delineation, residential environments are also based on resident's perception. Defining boundaries to residential neighborhoods is again based on home range and may be defined by roads as edges instead of administrative boundaries. It is multi-dimensional, dynamic changing with time, space, social groups, technology and lifestyle.

\section{PEOPLE}

- People is a plurality of persons considered as a whole as in an ethnic group or nation.

- The entire body of persons who constitute a community, tribe, nation or other group by virtue of a common culture, history, religion or the like.

- $\quad$ Persons whether men, women or children considered as numerable individuals forming a group.

\section{Table - 1 Parameters of built environment}

\begin{tabular}{|l|l|l|}
\hline S.no. & User group & Category \\
\hline 1 & Elderly men & Retired people \\
\hline 2 & $\begin{array}{l}\text { Elderly } \\
\text { women }\end{array}$ & “ \\
\hline 3 & Adult men & $\begin{array}{l}\text { Working } \\
\text { working people }\end{array}$ \\
\hline 4 & Adult women & “ \\
\hline 5 & Adolescents & $\begin{array}{l}\text { School /college going } \\
\text { or not going }\end{array}$ \\
\hline 6 & Children & “ \\
\hline
\end{tabular}

1. Physical Environment: It includes aspect of natural environment such as climate, terrain, temperature, rainfall, flora, fauna, etc.

2. Social -Cultural Environment: It includes all aspects of cultural environment such as norms, customs, process of socialization, etc. It includes all the aspects dealing with other people and their creations.

3. Environmental Orientations: It refers to the beliefs that people hold about their environment. For example, some people hold environment equivalent to God and therefore they perceive all its aspects with respect and reverence and try to maintain it in a perfect form and do not degrade it.

4. Environmental Behavior: It refers to the use of environment by people in the course of social interactions. For example, considering the environment as personal space, where the individual identifies himself with it.

5. Products of Behavior: These include the outcomes of people's actions such as homes, cities, dams, schools, etc. That is, these are products or outcomes dealing with the environment. All the above aspects of environment depict the important constituents of the study of interaction between environment and the human beings. 


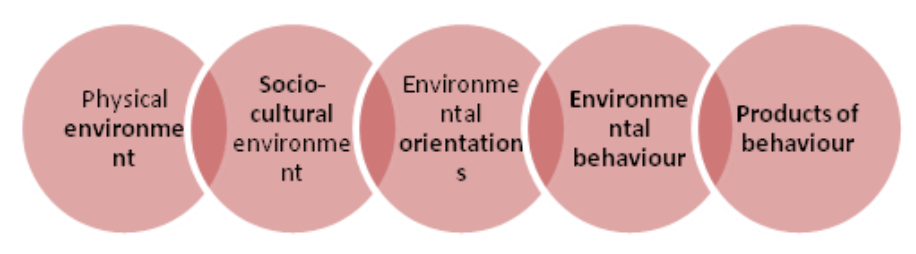

\section{Fig - 3 Five components of human-environment interaction}

${ }^{[5]}$ Kurt Lewin has introduced the concept of life space to explain the relationship between person and environment. According to Lewin, life space is the whole psychological reality that determines the behavior of an individual. Life space (L) includes everything present in the environment (E) that influences an individual's behavior. The environment (E) contains everything outside the person (P), including physical, psychological, and social aspects. Lewin calls the person $(\mathrm{P})$ in the environment $(\mathrm{E})$ as life space.

Mathematically, life space can be described as:

$$
\mathbf{B}=\mathbf{f}(\mathbf{L})=\mathbf{f}(\mathbf{P} . \mathbf{E}) \text {. }
$$

That is behavior of an individual at a particular time is a function of life space, which contains the person $(\mathrm{P})$ and environment $(\mathrm{E})$. The environment (E) in the life space influences individual's behavior and other physical environment that does not directly influence behavior that is called foreign hull. At some other time the events or objects in the foreign hull can influence the behavior of an individual, in that event the part of the foreign hull influencing the behavior becomes the part of $\mathrm{E}$ and $\mathrm{E}$ expands to include some part of the foreign hull.

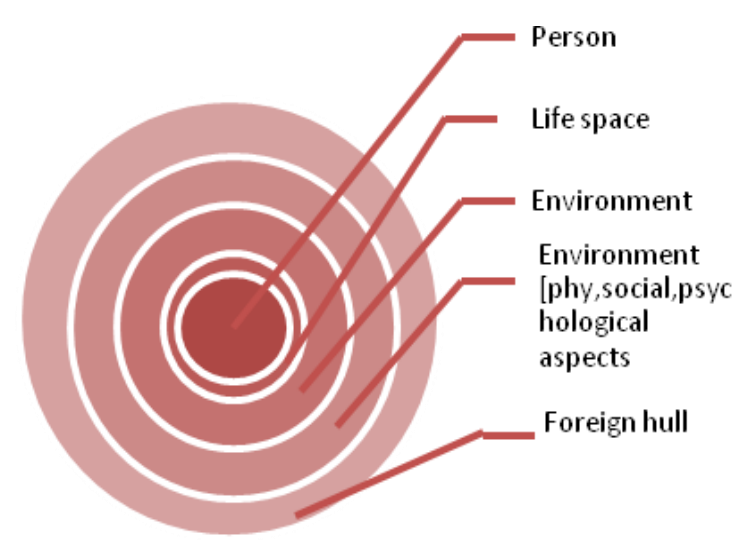

Fig - 4 Concept of Life Space

${ }^{[6]}$ Altman Irwin, "Some perspectives on the study of the man-environment phenomena", representative research in social psychology, vol-IV, no.1, published by the Dept. Of psychology, University of North Carolina at Chapel Hill. The author examines differences in value systems and approaches of behavioral scientists and practitioners in shaping the built environment for people, reviews briefly the history of relations between practitioners and scientists, and examines alternative philosophical models implicit in present day research in the field. 


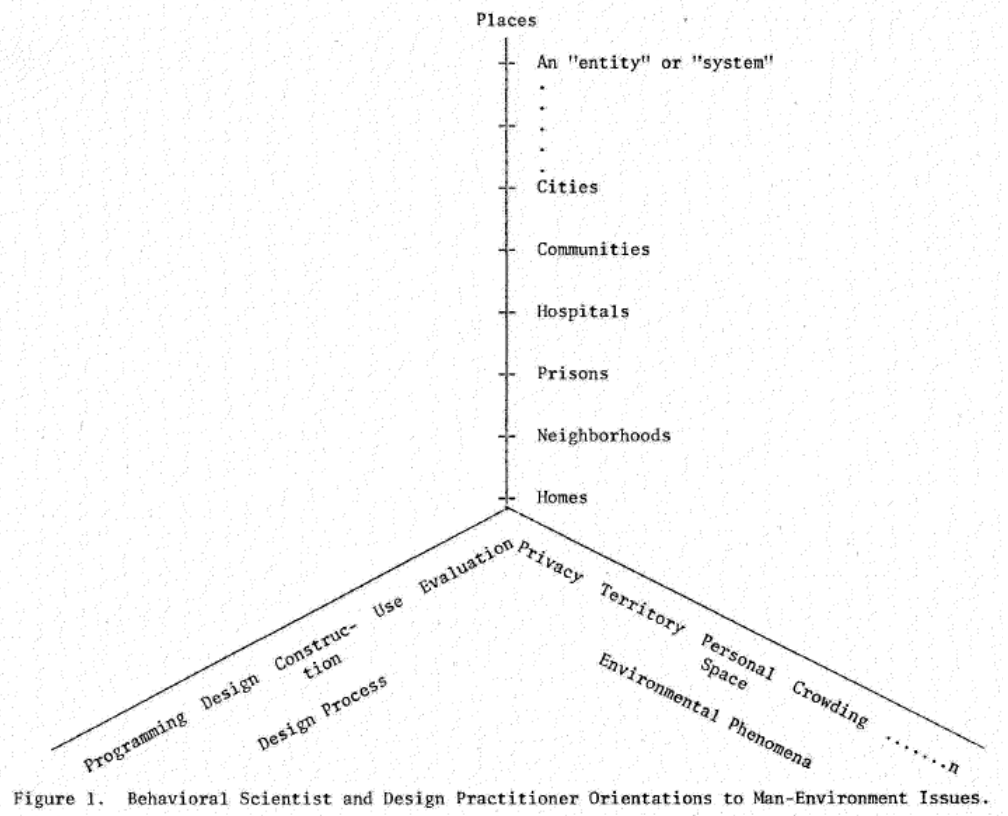

Fig - 5 Different orientations to man-environment issues

Researchers and practitioners have implicitly adopted one of several theoretical "models of man. The following models have served to guide research and practice:

1. A mechanistic model, with man viewed primarily as part of a complex man-machine system, and emphasis placed on performance-related behaviors;

2. A perceptual cognitive- motivational model, with man conceived of as an internal, subjective, inside-thehead processor. This model is presently popular in man-environment research, in the form of studies of cognitive maps and subjective reactions to environmental stimuli;

3. A behavioral model, which places emphasis on overt behavior rather than internal psychological processes. According to this position, man-environment relations are best understood through study of overt transactions between man and his physical environment;

4. an ecological, social systems model, which conceives of man-environment events as involving: (a) several behavioral levels, e.g., subjective internal process, overt verbal, nonverbal and environmental behaviors, which (b) function as a coherent system of interrelated, substitutable and complementary behaviors and (3) where there is a mutual relationship between environment and behavior, each influencing and shaping the other, (d) in a dynamic time-linked sense.

The position was taken that no single model is complete, but that the ecological social systems approach held considerable promise for understanding man-environment relations for several reasons:

1. It treats man and environments as the central units, not men alone or environments alone;

2. It holds the potential for bridging between the approaches of practitioners and researchers. That is, it calls for scientists to synthesize separate behavioral events into total organism units and calls for practitioners to examine social processes in an analytic fashion;

3. Its emphasis on multi-level behaviors brings together several areas of the behavioral and social sciences; and

5. It views man-environment relations in a way which stresses flexibility of environments and active organisms shaping environments.

\section{Residential Satisfaction Studies}

Resident's opinions about their neighborhoods offer important insights. They shed light on which aspects of the setting have a greater impact on the overall residential environment satisfaction.

${ }^{[7]}$ Herbert Gans stated that, "the effective environment may thus be defined as that version of the potential environment that is manifestly or latently adopted by the users", [Gans 1968]. Diener and Suh [1997] said that to understand the well being of an individual, one must measure the person's emotional and cognitive reactions to his/her environment.

The empirical studies dealing with residential satisfaction take one of the 2 approaches- 


\subsection{Approach -1}

1] ${ }^{[8]}$ Weidman and Anderson 1985: Speare 1974: Newman and Duncan 1979; Preiemus 1986 consider residential satisfaction as a predictor of behavior such as moving house or house improvement. ${ }^{[9]}$ Galster 1987 and Wolpert 1984 assume that any incongruence between the set of needs and aspirations and the current residential status can be alleviated either by moving or making adjustments to the current unit or location

\subsection{Approach -2}

2] ${ }^{[10} \mathrm{J}$ Marans and Rodgers 1975: ${ }^{[11]}$ Galster and Hesser 1988: Bonaiuto et.al 1999, ${ }^{[12]}$ Amerigo and Aragones 1990, 1997: ${ }^{[13]}$ Parkes et.al 2002: Pinquart and Burmedi 2004 consider that the residential satisfaction is related with residential quality. Factors like length of residence, tenure status, physical characteristics of house and neighborhoods social bonds and the socio-demographic characteristics of residents are said to affect satisfaction levels.

$3{ }^{[14]}$ Canter and Rees [1982] have used the multi dimensional scaling and developed a model that distinguishes 3 essential elements of the residential environment, the neighborhood, house and neighbors. This model places user goals at the center of evaluation of the residential environment. Here feedback or appraisal is important to design process. Study by Amerigo et.al aimed at deriving the predictors of residential satisfaction in public housing of the city of Madrid. The results show that psycho-social aspects such as relationships with neighbours and the degree of attachment to the residential environment are stronger predictors than physical features such as infrastructures etc.

Tognoli, 1987; Lawrence 2002 conducted a research in environmental psychology that focused on the relationship between people and residential environment on different levels of home, neighbourhood and city. Out of these neighborhoods was chosen for study due to the following reasons -

1] It allows considering private and public structures and processes

2] Earlier studies showed that it serves as a link between home and city.

${ }^{[15]}$ Bonnes et.al 1997 has given a measure of residential satisfaction consisting of a series of scales measuring perceived residential environment quality and a scale measuring neighborhoods attachment. It has also given the 4 generative criteria's as spatial, human, functional and context.

The area of study can be neighborhoods defined by people's perception with 3 features of -residential environment, house and neighbours. As regards the residential satisfaction studies, man being a social animal, the satisfaction with the sub-domain as social climate, social interactions or social capital is the most significant component of overall residential satisfaction. Hence increasing the focus towards the incidental spaces in the residential environment.

1] ${ }^{[6]}$ Frank Wassenberg and Roland Goetgeluk, "Measuring the residential environment", paper for the conference Doing, thinking, feeling home: the mental geography of residential environments, OTB research institute, Tu delft, the Netherlands. The paper focuses on the concept of neighborhood and residential environment. The difference in viewpoints of the scientists, planners, politicians and finally the residents have been analyzed in a way to bring issues on a common platform by drawing the neighborhood hexagon, using mental mapping methods concentrating on perception,use,behaviour,wishes and satisfaction.

2] ${ }^{[17]}$ Rama.P.U,Garg.Y.,Bharat Alka,"A framework for evaluating residential built environment performance for livability", ITPI journal,Dec'2010. The paper intended to identify the parameters that effect the built environment characteristics and its influence on livability. The paper suggested the quantitative framework to assess the living conditions of residential areas with regard to their physical built environments.

3] ${ }^{[18]}$ Marino Bonaiuto, Ferdinando Fornara, Mirilia Bonnes:, "Indexes of perceived residential environment quality and neighborhood attachment in urban environments: a confirmation study on the city of Rome", landscape and urban planning 65[2003]41-52. Presents two instruments measuring the quality of the relationship that inhabitants have with their urban neighborhoods. These instruments consist of 11 scales measuring the perceived environmental qualities of urban neighborhoods and one scale measuring neighborhood attachment. The 11 scales are included in four generative criteria as follows: 3 scales concern spatial aspects (i.e. architectural-planning space, organization and accessibility of space, green space); one concerns human aspects (i.e. people and social relations); four concern functional aspects (i.e. welfare, recreational, commercial, transport services); three concern contextual aspects (i.e. pace of life, environmental health, upkeep). A series of Principal Component Analyses (PCA) was performed on the data. Results confirm the factorial structure of the scales, which include 19 perceived quality indexes (150 items total) and one neighborhood attachment index (eight items).

4] ${ }^{[19]}$ Leyden M. Kevin, "Social capital and the built environment: the importance of the walk able neighborhoods", American journal of public health, Sep '2003

To examine whether pedestrian-oriented, mixed-use neighborhoods encourage enhanced levels of social and community engagement from a household survey that measured the social capital of citizens living in neighborhoods that ranged from traditional, mixed-use, pedestrian-oriented designs to modern, car-dependent suburban subdivisions in Galway, Ireland The analyses indicate that persons living in walk able, mixed-use 
neighborhoods have higher levels of social capital compared with those living in car-oriented suburbs. Respondents living in walk able neighborhoods were more likely to know their neighbors, participate politically, trust others, and be socially engaged.

\section{Conclusion}

Residential satisfaction is more a function of the social capital of a neighborhood and enhancing it by the use of incidental open spaces along with the interdependent communities may help achieve better environments. Empirical studies have examined characteristic of the users or of the environment both physical and social and these variables can be organized in a model in an effort to facilitate analysis of the relationships among the characteristics.

\section{References}

[1] The Built Environment, a collaboration inquiry into Design and Planning, second edition, 2007, edited by Wendy R. McClure and Tom J. Bartuska

[2] Churchman and Rosenfeld [1978] Churchman, A., \& Rosenfeld, N., Some Guidelines for the design of residential areas: The precinct level. Final Report: Innovations and Improvements in Housing. Technion, Faculty of Architecture \& Town Planning, 1978 (Hebrew).

[3] Hallman,H.W.[1984].Neighbourhoods: Their place in urban life.Beverley Hills,CA:Sage Publications.

[4] Rappoport [1980-81, 1997] Amos Rappoport(1969),House form and culture,NJ,Prentice Hall Lewin, K. (1935) A dynamic theory of personality. New York: McGraw-Hill.

[6] Altman Irwin, "Some perspectives on the study of the man-environment phenomena", representative research in social psychology, vol-IV, no.1, published by the Dept. Of psychology, University of North Carolina at Chapel Hill.

[7] Herbert Gans[1968].People and Plans, essays on urban problems and solutions.New York/London:Basic Books.

[8] Weidman and Anderson 1985.A conceptual framework for residential satisfaction.In I. Altman \& Werner, Home Environments, New York:Plenum press.

[9] Galster,G.(1987),'Identifying the correlates of dwelling satisfaction: an empirica critique", Environment and Behaviour 19(5),539568.

[10] Marans and Rodgers 1975Marans, R.W., Rodgers, W., 1975. Toward an understanding of community satisfaction. In: Hawley, A., Rock, V. (Eds.), Metropolitan America in Contemporary Perspective. Halsted Press, New York.

[11] Galster,G.C. and G.W.Hesser(1981), "Residential satisfaction:compositional and contextual correlates", Environment and Behaviour 13(6),735-758.

[12] Amerigo,M. and J.J.Aragoneses(1990),'Residential satisfaction in council housing”,Journal of Environmental Psychology 10,313 325 .

[13] Parkes,A.A.Kearns, and R.Atkinson(2002),"What makes people dissatisfied with their neighbourhoods", Urban Studies 39(13), 2413-2438.

[14] Canter and Rees [1982].A multivariate model of housing satisfaction.International Review of Applied Psychology,31,185-207

[15] Bonnes, M., Bonaiuto, M., Aiello A., Perugini, M., Ercolani, A.P. (1997). A transactional perspective on residential satisfaction. In C. Despres, D. Piché (Eds.), Housing surveys : Advances in theory and methods (pp. 99-135). Quebec, Canada: Crad

16] Frank Wassenberg and Roland Goetgeluk, "Measuring the residential environment", paper for the conference Doing, thinking, feeling home: the mental geography of residential environments, OTB research institute, Tu delft, the Netherlands.

[17] Rama.P.U,Garg.Y.,Bharat Alka," A framework for evaluating residential built environment performance for livability” ,ITPI journal,Dec'2010.

[18] Marino Bonaiuto, Ferdinando Fornara, Mirilia Bonnes:, "Indexes of perceived residential environment quality and neighborhood attachment in urban environments: a confirmation study on the city of Rome", landscape and urban planning 65[2003]41-52.

[19] Leyden M. Kevin, "Social capital and the built environment: the importance of the walk able neighborhoods", American journal of public health, Sep '2003 